\title{
Superfosfato triplo como via de distribuição de sementes de Brachiaria brizantha para renovação de pastagens na Amazônia
}

\author{
Eduardo do Valle Lima ${ }^{1}$, José Cláudio de Sousa Tavares ${ }^{2}$, Eliane Carvalho Silva ${ }^{3}$, Patrícia da \\ Silva Leitão-Lima ${ }^{1}$
}

\author{
1 Universidade Federal Rural da Amazônia. \\ 2 Curso de Graduação em Zootecnia da UFRA - Parauapebas-PA. Bolsista PIBIC/CNPq/UFRA. \\ ${ }^{3}$ Curso de Graduação em Zootecnia da UFRA - Parauapebas-PA. Bolsista de Extensão da UFRA.
}

RESUMO - Objetivou-se estudar o efeito de dez tempos de contato (0, 3, 6, 12, 24, 36, 48, 72, 96 e 120 horas) do fertilizante químico granulado superfosfato triplo com sementes de Brachiaria brizantha, cv. Marandu, na sua qualidade fisiológica (germinação e vigor). O delineamento experimental utilizado foi o inteiramente casualizado, com quatro repetições, tanto para a condição de laboratório quanto para a condição de viveiro. O tempo de contato do fertilizante com as sementes teve efeito significativo sobre todas as variáveis analisadas, portanto, provavelmente o resíduo do ácido fosfórico do fertilizante teve influência direta e negativa na germinação e no vigor, comprovada pelos resultados de germinação, primeira contagem, teor de água, condutividade elétrica, emergência e índice de velocidade de emergência. Assim, para obtenção de uma população adequada de plantas, pode-se misturar as sementes da forrageira com o superfosfato triplo, desde que a semeadura seja imediata, o que diminui as perdas na qualidade fisiológica.

Palavra-chave: adubo químico, braquiária, emergência, fertilizante fosfatado, tempo de contato, vigor

\section{Triple superphosphate as a means to distribute Brachiaria brizantha seeds for pasture renovation in the Amazon Region}

\begin{abstract}
This study aimed to determine the effect of 10 contact times of a granular triple superphosphate chemical fertilizer with Brachiaria brizantha, cv. Marandu seeds on seed physiological quality (germination and vigor). Contact times were: $0,3,6,12,24,36,48,72,96$, and 120 hours. A completely randomized experimental design was used, with four replicates, under both laboratory and nursery conditions. In all variables studied, a significant effect of the treatments employed was observed: as contact time with the fertilizer increased, the phosphoric acid residue from the fertilizer probably had a direct and negative effect on germination and vigor, as observed by germination, first count, water content, electric conductivity, emergence, and emergence velocity index results. Therefore, in order to obtain an adequate population of plants, the forage seeds can be mixed with the triple superphosphate since seeding is performed immediately, reducing physiological quality losses.
\end{abstract}

Key Words: brachiaria, chemical fertilizer, contact time, emergence, phosphate fertilizer, vigor

\section{Introdução}

As pastagens no Brasil, em sua maioria, têm sido implantadas em áreas com solos de baixa fertilidade natural ou foram induzidas por práticas agrícolas inadequadas (Cavariani et al., 1994). De modo geral, na região amazônica, as pastagens estão assentadas basicamente sobre dois tipos de solo: Latossolo e Podzólico, ambos de baixa fertilidade (Teixeira \& Simão Neto, 2000). A deficiência natural de fósforo nesses tipos de solo, aliada à alta fixação desse elemento, torna a adubação fosfatada uma prática necessária para o estabelecimento, a manutenção da longevidade e a sustentabilidade das pastagens (Teixeira et al., 2000).

A renovação de pastagem depende de um conjunto de técnicas que se aplicam a uma pastagem cultivada em estado de degradação. Na renovação de B. brizantha, deve-se dar maior atenção durante a operação de semeadura, uma vez que o estabelecimento incorreto da pastagem pode acarretar degradação precoce, pela má formação do estande (Dias-Filho, 2005). Entretanto, o tamanho reduzido das sementes dificulta sua distribuição uniforme e a conseqüente população ideal de plantas, pois muitos produtores não possuem semeadora-adubadora apropriada. Dessa 
forma, pode-se realizar a mistura das sementes de Brachiaria brizantha com fertilizantes fosfatados visando à utilização do adubo como via de transporte, além de servir como adubação de plantio (Soratto et al., 2003).

Assim, quando há necessidade de aplicar apenas fóforo misturado à semente de $B$. brizantha na renovação de pastagem, podem-se utilizar fosfatos solúveis, como o superfosfato triplo (SFT). Entretanto, no seu processo de fabricação, o superfosfato triplo sofre o ataque do ácido forte, sobretudo o fosfórico $\left(\mathrm{H}_{2} \mathrm{PO}_{4}\right)$, por isso, possui resíduo ácido capaz de influenciar negativamente não só a germinação (Sader et al., 1991), mas também o vigor, diminuindo o número de plântulas emersas (Cavariani et al., 1994). Entretanto, Mateus et al. (2007), em pesquisa com a mesma espécie e o mesmo fertilizante, concluíram que a mistura realizada até 96 horas antes da semeadura não prejudica a emergência das plântulas.

Neste contexto, objetivou-se avaliar o efeito dos tempos de contato $(0,3,6,12,24,36,48,72,96$ e 120 horas $)$ do superfosfato triplo na qualidade fisiológica (germinação e vigor) de sementes de Brachiaria brizantha visando à renovação de pastagens na Amazônia.

\section{Material e Métodos}

O trabalho foi realizado na Unidade Descentralizada de Parauapebas - UDP, Campus de Carajás, da Universidade Federal Rural da Amazônia (UFRA), em Parauapebas, no Laboratório Multidisciplinar do Centro Universitário de Parauapebas, CEUP, sob condições de viveiro com $50 \%$ de sombreamento, no período de fevereiro a julho de 2006.

Utilizou-se o delineamento experimental inteiramente casualizado, com quatro repetições, de modo que os tratamentos foram constituídos dos períodos de contato de sementes de B. brizantha, cv. Marandu (0, 3, 6, 12, 24, 36, $48,72,96$ e 120 horas), com o fertilizante químico granulado superfosfato triplo $\left[\mathrm{Ca}\left(\mathrm{H}_{2} \mathrm{PO}_{4}\right)_{2}\right]$. A B. brizantha, cv. Marandu, foi escolhida para utilização no experimento porque compõe aproximadamente $90 \%$ das gramíneas forrageiras cultivadas na região (Teixeira et al., 2000).

As sementes foram adquiridas em embalagem comercial hermeticamente fechada, fiscalizadas, com potencial de germinação de $80 \%$, pureza mínima igual a $40 \%$ e valor cultural de $32 \%$, dentro do prazo de validade. As sementes puras viáveis (SPV) foram separadas utilizando-se pinças e pincéis e armazenadas provisoriamente em sacos de papel no laboratório. Definiu-se como taxa de semeadura ideal a quantidade de $5 \mathrm{~kg}$ de SPV/ha, recomendada pela Embrapa (2004) para situações menos favoráveis na implantação de pastagens.
A quantidade de adubo para a mistura com as sementes foi definida conforme recomendação máxima para adubação de formação de pastagem de $B$. brizantha, $80 \mathrm{~kg} / \mathrm{ha}$ de $\mathrm{P}_{2} \mathrm{O}_{5}$, o que corresponde a $177,8 \mathrm{~kg} /$ ha de SFT (Van Raij et al., 1997). Portanto, a proporção da mistura foi de $8,9 \mathrm{~kg}$ de superfosfato triplo para cada $0,25 \mathrm{~kg}$ de sementes puras viáveis.

Momentos antes da mistura, foi retirada uma amostra de sementes correspondente ao tratamento testemunha (sem contato com o fertilizante), enquanto o restante foi misturado homogeneamente ao fertilizante granulado. Posteriormente, a mistura foi acondicionada em embalagem plástica, hermeticamente fechada e mantida em condições de laboratório. Nesta condição, efetuou-se durante o experimento a aferição diária de temperaturas máximas e mínimas do laboratório. Como praticamente não houve variações substanciais, pode-se afirmar que a média das temperaturas máximas foi de $28,4^{\circ} \mathrm{C}$ e a média das temperaturas mínimas, de $26,3^{\circ} \mathrm{C}$.

Decorridos os tempos de contato preestabelecidos (3, 6, 12, 24, 36, 48, 72, 96 e 120 horas), foram retirados aleatoriamente $200 \mathrm{~g}$ da mistura para cada tempo de contato. Em $100 \mathrm{~g}$ dessas alíquotas, separaram-se de forma manual, com a utilização de pincéis, as sementes dos adubos para determinação laboratorial do teor de água, pelo método da estufa a $105^{\circ} \mathrm{C}$, admitindo-se variação de $3^{\circ} \mathrm{C}$ durante o período de 24 horas (Brasil, 1992). Utilizaram-se duas repetições para cada tempo de contato colocando-se aproximadamente $4 \mathrm{~g}$ de sementes puras viáveis em cápsulas de alumínio. Os resultados foram expressos em porcentagem, com base no peso úmido das amostras.

Realizou-se o teste padrão de germinação para as sementes de braquiária, segundo Brasil (1992). Para cada tempo de contato, utilizaram-se quatro caixas plásticas quadradas do tipo gerbox contendo no fundo duas folhas de papel substrato germiteste. Com o auxílio de pinças, foram colocadas 50 sementes em cada caixa, dispostas de forma eqüidistante. As sementes foram umedecidas inicialmente com $12 \mathrm{~mL}$ de água destilada, mantendo-se a umidade necessária durante todo o teste. As caixas foram cobertas com plástico transparente para diminuir as perdas de água e colocadas em câmara germinadora regulada para período de 8 horas diárias a $35^{\circ} \mathrm{C}$ e período de 16 horas a $25^{\circ} \mathrm{C}$, sem luz. Após sete dias, realizou-se a primeira contagem de emergência das plântulas (teste de vigor), removendo-se aquelas suficientemente crescidas e com todas as suas estruturas essenciais bem formadas (Brasil, 1992). Decorridos 21 dias, realizou-se a contagem final, determinando-se o número total de plântulas normais. Neste caso, considerando a primeira contagem, obteve-se a porcentagem de 
germinação correspondente ao número de sementes utilizadas que produziram plântulas normais sob condições ideais de laboratório (teste de germinação).

A condutividade elétrica (teste de vigor) das sementes de braquiária foi determinada utilizando-se quatro subamostras de 50 sementes para cadatempo de contato, as quais foram pesadas em balança analítica de precisão $(0,001 \mathrm{~g})$ e colocadas em copo de plástico com $75 \mathrm{~mL}$ de água destilada, mantido em câmara a $25^{\circ} \mathrm{C}$ durante 24 horas. Em seguida, realizou-se a leitura do exudado das sementes contido na água com condutivímetro, para o valor em relação ao peso inicial das sementes, expresso em $\mu \mathrm{S} / \mathrm{cm} . \mathrm{g}(\mathrm{AOSA}, 1983)$.

Paralelamente, parte das sementes mantidas em contato com o fertilizante ou separadas do adubo (a outra alíquota de $100 \mathrm{~g}$ ) foi submetida a avaliações em condições de viveiro (simulação de campo). Assim, foram semeadas manualmente 50 sementes utilizando-se pinças, em sacolas plásticas de $2 \mathrm{~L}$ com terra, com quatro repetições por tempo de contato. A terra foi retirada da camada arável $(0-20 \mathrm{~cm})$ de um solo com as seguintes características: $\mathrm{pH}\left(\mathrm{H}_{2} \mathrm{O}\right)=$ 5,33 ; matéria orgânica $=29,85 \% ; \mathrm{P}=1,18 \mathrm{mg} / \mathrm{dm}^{3} ; \mathrm{H}+\mathrm{Al}=$ $44,4 \mathrm{mmol}_{\mathrm{c}} / \mathrm{dm}^{3} ; \mathrm{K}, \mathrm{Ca}$ e $\mathrm{Mg}$ trocáveis $=2,7 ; 40,4$; $12,4 \mathrm{mmol}_{\mathrm{c}} / \mathrm{dm}^{3}$, respectivamente; $\mathrm{SB}=55,5 ; \mathrm{CTC}=$ $99,9 \mathrm{mmol}_{\mathrm{c}} / \mathrm{dm}^{3} ; \mathrm{V} \%=55,6$. As sacolas plásticas foram mantidas sob $50 \%$ de sombreamento, conservando a umidade da terra sempre próxima a $70 \%$ da capacidade de campo. A primeira contagem foi realizada sete dias após a semeadura para obtenção da porcentagem de emergência (teste de vigor). Posteriormente, realizaram-se contagens diárias do número de plântulas emergidas para determinação do índice de velocidade de emergência - IVE (teste de vigor), calculado de acordo com a fórmula: IVE $=\mathrm{N} 1 / \mathrm{D}_{1}+$ $\mathrm{N}_{2} / \mathrm{D}_{2}+\ldots+\mathrm{N}_{\mathrm{n}} / \mathrm{D}_{\mathrm{n}}$, em que $\mathrm{N}_{1}, \mathrm{~N}_{2}, \mathrm{~N}_{\mathrm{n}}=$ número de plântulas emergidas no $1^{\mathrm{o}}, 2^{\mathrm{o}}$ e $\mathrm{n}$ número de dias após o teste até a estabilização; $\mathrm{D}_{1}, \mathrm{D}_{2}, \mathrm{D}_{\mathrm{n}}=$ número de dias após a implantação do teste (Maguire, 1962).

Os dados obtidos foram submetidos à análise de variância e ao teste $\mathrm{F}$ e as médias foram comparadas pelo teste Tukey a 5\%. Também foram realizadas análises de regressão polinomial ajustando-se as equações para as variáveis analisadas, selecionando as regressões com maior coeficiente de correlação $\left(\mathrm{R}^{2}\right)$ entre as significativas pelo teste $\mathrm{F}$. Todos os cálculos foram realizados por meio do programa de computador ESTAT, conforme método descrito por Banzato \& Kronka (1989).

\section{Resultados e Discussão}

O período de contato das sementes de Brachiaria brizantha, cv. Marandu, com o fertilizante superfosfato triplo influenciou a taxa de germinação, a primeira contagem, o teor de água e a condutividade elétrica das sementes (Tabela 1).

Logo após a mistura, constatou-se efeito negativo do contato do fertilizante sobre a germinação e a primeira contagem das sementes (Tabela 1). A diminuição dessas variáveis ocorreu progressivamente com o tempo de contato, seguindo um padrão linear de comportamento (Tabela 2).

A germinação e primeira contagem a partir do tempo de contato de 72 horas apresentaram os piores valores em comparação ao tempo de 24 horas de contato, que, mesmo assim, já havia apresentado redução superior a $50 \%$ em relação à testemunha (Tabela 1). Efeito similar para germinação foi observado por Soratto et al. (2003) em estudo sobre o efeito do tempo de contato do mesmo fertilizante sobre a germinação de sementes de milheto (Pennisetum glaucum). Esses autores observaram redução linear da

Tabela 1 - Germinação, primeira contagem, teor de água e condutividade elétrica de sementes de Brachiaria brizantha, cv. Marandu, em diversos tempos de contato com o fertilizante granulado superfosfato triplo

\begin{tabular}{|c|c|c|c|c|}
\hline Tempo de mistura (horas) & Germinação & Primeira contagem & Teor de água & Condutividade elétrica $(\mu \mathrm{S} / \mathrm{cm} . \mathrm{g})$ \\
\hline 0 & $50,0 \mathrm{a}$ & $47,0 \mathrm{a}$ & $10,9 \mathrm{~d}$ & $88,9 \mathrm{~d}$ \\
\hline 3 & $39,5 \mathrm{ab}$ & $35,0 \mathrm{~b}$ & $10,9 d$ & $125,6 \mathrm{~cd}$ \\
\hline 6 & $29,5 \mathrm{bc}$ & $25,5 \mathrm{bc}$ & $10,9 \mathrm{~d}$ & $134,6 \mathrm{~cd}$ \\
\hline 12 & $28,0 \mathrm{bc}$ & $21,5 \mathrm{c}$ & $11,0 \mathrm{~cd}$ & $142,6 \mathrm{~cd}$ \\
\hline 24 & $20,0 \mathrm{~cd}$ & $17,0 \mathrm{~cd}$ & $11,2 \mathrm{bcd}$ & $157,6 \mathrm{~cd}$ \\
\hline 36 & $12,5 \mathrm{de}$ & $10,5 \mathrm{de}$ & $11,2 \mathrm{abcd}$ & $143,6 \mathrm{~cd}$ \\
\hline 48 & $12,5 \mathrm{de}$ & $10,0 \mathrm{de}$ & $11,3 \mathrm{abc}$ & $159,2 \mathrm{bcd}$ \\
\hline 72 & $7,0 \mathrm{e}$ & $5,5 \mathrm{e}$ & $11,3 \mathrm{abc}$ & $194,3 \mathrm{abc}$ \\
\hline 96 & $4,5 \mathrm{e}$ & $2,0 \mathrm{e}$ & $11,5 \mathrm{ab}$ & $243,9 \mathrm{a}$ \\
\hline 120 & $2,0 \mathrm{e}$ & $2,0 \mathrm{e}$ & $11,6 \mathrm{a}$ & $238,6 a b$ \\
\hline Valor de F & $38,2 * *$ & $50,9 * *$ & $17,3 * *$ & $8,8 * *$ \\
\hline CV (\%) & 25,0 & 23,7 & 0,74 & 20,4 \\
\hline
\end{tabular}

Médias seguidas de mesma letra na coluna não diferem entre si a $5 \%$ pelo teste Tukey.

** significativo a $1 \%$ pelo teste $\mathrm{F}$. 
Tabela 2 - Equações de regressão ajustadas para a qualidade fisiológica das sementes (germinação e vigor) de sementes de B. brizantha cv. Marandu (y) em diversos tempos de contato com o fertilizante granulado superfosfato triplo $(\mathrm{x})$

\begin{tabular}{|c|c|c|}
\hline Variável & Equação & $r^{2}$ \\
\hline Germinação (\%) & $\hat{y}=-0,3316 x+34,379$ & $0,76 * *$ \\
\hline Primeira contagem $(\%)$ & $\hat{y}=-0,2998 x+30,1$ & $0,71 *$ \\
\hline Teor de água (\%) & $\hat{y}=-3 E-05 x^{2}+0,009 x+10,898$ & $0,96^{*}$ \\
\hline $\begin{array}{l}\text { Condutividade } \\
\text { elétrica }(\mu \mathrm{S} / \mathrm{cm} / \mathrm{g})\end{array}$ & $\hat{y}=1,1156 x+116,37$ & 0,90 \\
\hline Emergência $(\%)$ & $\hat{y}=-0,2221 x+20,312$ & $0,55^{*}$ \\
\hline $\begin{array}{l}\text { Índice de velocidade } \\
\text { de emergência }\end{array}$ & $\hat{y}=-0,4135 x+38,071$ & $0,78 *$ \\
\hline
\end{tabular}

$*=\mathrm{P}<(0,05) \mathrm{e}^{* *}=\mathrm{P}<(0,01)$

germinação das sementes com o tempo de contato. Assim, conforme relatado por Lima et al. (2000), provavelmente houve efeito prejudicial do tempo de contato das sementes com o fertilizante sobre a taxa de germinação e a primeira contagem, provavelmente pelo fato de o adubo ser obtido por processo de via ácida. Portanto, após o processamento da rocha fosfatada com o ácido fosfórico, o resíduo deste ácido, mesmo após lavagem, é capaz de influenciar direta e negativamente a germinação e ovigor das sementes, efeito que é acentuado com o maior período de contato (Lima et al., 2000).

Com o aumento do tempo de contato do fertilizante com as sementes, o teor de água das sementes reduziu (Tabela 1); o tempo de até 6 horas de contato foi inferior estatisticamente aos contatos a partir de 48 horas. Entretanto, tempos de contato intermediários, como 12, 24 e 36 horas, foram iguais aos demais, fato explicado pelo baixo $\mathrm{pH}$ do superfosfato triplo (Lima et al., 2000), que proporcionou o rompimento do tegumento da semente (Soratto et al., 2003), possibilitando a entrada de umidade do ambiente.

A condutividade elétrica das sementes de $B$. brizantha aumentou de acordo com o tempo de contato com o superfosfato triplo, o que comprova relação inversa entre essa variável com a germinação e a primeira contagem (Tabela 1). Assim, a manutenção das sementes sem fertilizante resultou no menor valor de condutividade elétrica, de modo que, no tempo de contato, os valores foram aumentando de forma linear (Tabela 2), o que indica provável efeito deletério do adubo (resíduo ácido) sobre o tegumento das sementes, ocasionando extravasamento dos eletrólitos que estavam na substância de reserva das sementes. Dados semelhantes foram obtidos por Soratto et al. (2003), que estudaram o efeito do superfosfato triplo em sementes de milheto e constataram aumento gradual no transcorrer do tempo de contato.

$\mathrm{Na}$ emergência das sementes em condições de campo após mistura sem a presença do adubo, nos tempos de até 12 horas de contato, os resultados foram superiores estatisticamente às médias obtidas a partir do tempo de 36 horas de contato (Tabela 3 ). O índice de velocidade de emergência obtido nos tempos de até 24 horas de contato foram superiores às médias obtidas a partir de 36 horas de contato. Tanto a emergência quanto o índice de velocidade de emergência apresentaram decréscimo linear com o transcorrer do tempo de contato da mistura. Ao contrário, os resultados obtidos por Mateus et al. (2007) comprovaram que o tempo de contato do superfosfato triplo não teve efeito sobre a emergência e o índice de velocidade de emergência, apesar de o tempo de mistura ter influenciado a germinação em laboratório. Esse efeito diferenciado entre laboratório e campo parece não ter sustentabilidade prática e teórica, pois o que se espera de um mesmo tratamento aplicado em condições ideais de laboratório e em condições diversas de campo é que os dois resultados apresentem pelo menos similaridade, fato verificado neste trabalho para germinação e primeira contagem (laboratório) com emergência e índice de velocidade de emergência (campo). Neste estudo, os dados de emergência, apesar de terem sido baixos na primeira contagem e na germinação, em virtude das influências adversas do ambiente, sofreram praticamente o mesmo efeito no decorrer do tempo de contato.

Portanto, o ideal seria realizar a semeadura logo após a mistura para reduzir os danos à qualidade fisiológica das

Tabela 3 - Emergência e índice de velocidade de emergência de sementes de Brachiaria brizantha, cv. Marandu em diversos tempos de contato com fertilizante granulado superfosfato triplo

\begin{tabular}{lcc}
\hline Tempo de mistura (horas) & \multicolumn{2}{c}{ Semeadura (semente) } \\
\cline { 2 - 3 } & Emergência $(\%)$ & $\begin{array}{c}\text { Índice de velocidade } \\
\text { de emergência }\end{array}$ \\
\hline 0 & $25,5 \mathrm{a}$ & $49,0 \mathrm{a}$ \\
3 & $22,0 \mathrm{a}$ & $40,5 \mathrm{ab}$ \\
6 & $25,0 \mathrm{a}$ & $43,9 \mathrm{ab}$ \\
12 & $18,5 \mathrm{ab}$ & $32,7 \mathrm{bc}$ \\
24 & $11,0 \mathrm{bc}$ & $25,5 \mathrm{c}$ \\
36 & $4,5 \mathrm{~cd}$ & $9,3 \mathrm{~d}$ \\
48 & $2,5 \mathrm{~d}$ & $4,8 \mathrm{~d}$ \\
72 & $1,0 \mathrm{~d}$ & $1,7 \mathrm{~d}$ \\
96 & $0,5 \mathrm{~d}$ & $0,9 \mathrm{~d}$ \\
120 & $0,0 \mathrm{~d}$ & $0,0 \mathrm{~d}$ \\
Valor de F & $42,5 * *$ & $46,8 * *$ \\
CV $(\%)$ & 29,7 & 27,5 \\
\hline
\end{tabular}

Médias seguidas de mesma letra na coluna não diferem entre si a $5 \%$ pelo teste Tukey. $* *$ significativo a $1 \%$ pelo teste $\mathrm{F}$. 
sementes e evitar perdas de germinação e vigor que possam interferir na boa formação do novo pasto. Em termos práticos, pode-se considerar certa flexibilidade, pois problemas inesperados em campo podem ocorrer, como a quebra de máquinas ou a ocorrência de chuvas. Assim, para que a perda gradativa na qualidade fisiológica não prejudique a formação do estande, a mistura das sementes com o superfosfato triplo deve ser feita somente em quantidade possível de ser semeada em um período do dia, manhã ou tarde, não superior a 6 horas após a mistura.

\section{Conclusões}

Quanto maior o tempo de contato das sementes de Brachiaria brizantha com o fertilizante superfosfato triplo, maiores os danos à qualidade fisiológica das sementes e as perdas de germinação e vigor. A mistura de sementes de $B$. brizantha com superfosfato triplo para a renovação de pastagens pode ser recomendada desde que a semeadura seja imediata, até 6 horas após a mistura.

\section{Literatura Citada}

ASSOCIATION OF OFFICIAL SEED ANALYSIS - AOSA. Seed vigour testing handbook. East Lansing: 1983. 88p.

BANZATO, D.A.; KRONKA, S.N. Experimentação agrícola. Jaboticabal: FUNEP, 1989. 247p.

BRASIL. Ministério da Agricultura e Reforma Agrária. Regras para análise de sementes. Brasília: SNAD/DNDV/CLAV, 1992. 365p.

CAVARIANI, C.; NAKAGAWA, J.; VELINIL, E.D. Mistura de fertilizantes fosfatados com sementes de Brachiaria decumbens
Stapf e Brachiaria brizantha (Hochst. Ex A. Rich) Stapf. Revista Brasileira de Sementes, v.16, n.2, p.163-167, 1994. DIAS FILHO, M.B. Degradação de pastagens: processo, causas e estratégias de recuperação. 2.ed. Belém: Embrapa Amazônia Oriental, 2005. 173p.

EMPRESA BRASILEIRA DE PESQUISA E AGROPECUÁRIA EMBRAPA. Forrageira: Brachiaria brizantha, cv. Xaraés. Campo Grande: Centro Nacional de Pesquisa de Gado de Corte, 2004. (Folheto)

LIMA, E.V.; CAVARIANI, C.; LIMA, P.L. et al. Qualidade fisiológica de sementes de painço (Panicum dichotomiflorum Mix.) em função do tempo de mistura com o superfosfato triplo. Cultura Agronômica, v.9, n.1, p.177-189, 2000.

MAGUIRE, L.D. Speed of germination - aid in selection and evolution for seedling emergence and vigor. Crop Science, v.2, n.2, p.176-7, 1962.

MATEUS, G.P.; BORGHI, E.; MARQUES, R.R. et al. Fontes e períodos de contato de fertilizantes e germinação de sementes de Brachiaria brizantha. Revista Brasileira de Ciência do Solo, v.31, p.177-183, 2007.

Van RAIJ, B.; CANTARElla, H.; QUAGgio, J.A. et al. Recomendações de adubação e calagem para o estado de São Paulo. 2.ed. Campinas: Instituto Agronômico e Fundação IAC, 1997. 285p. (Boletim Técnico, 100).

SADER, R.; GAVIOLI, E.A.; MATTOS JR., D. et al. Efeito da mistura de fertilizantes fosfatados na germinação de sementes de Brachiaria brizantha (Hochst Ex A. Rich) Stapf. e de Brachiaria decumbens Stapf. Revista Brasileira de Sementes, v.13, n.1, p.37-43, 1991.

SORATTO, R.P.; LIMA, E.V.; MAUAD, M. et al. Millet seeds mixed with phosphate fertilizers. Scientia Agricola, v.60, n.3, p.573-579, 2003.

TEIXEIRA, L.B.; SIMÃO NETO, M.; TEIXEIRA NETO, J.F. Pesquisas com pastagens cultivadas na Amazônia. In: COSTA, N.A. (Ed.) Pastagens cultivadas na Amazônia. Belém: Embrapa Amazônia Oriental, 2000. p.17-35.

TEIXEIRA, L.B.; SIMÃO NETO, M. Renovação e adubação de pastagens. In: COSTA, N.A.; MOURA CARVALHO, L.O.D.; TEIXEIRA, L.B. et al. (Eds.) Pastagens cultivadas na Amazônia. Belém: Embrapa Amazônia Oriental, 2000. p.113-136. 